\title{
Decrypting Transition States by Light: Photoisomerization as a Mechanistic Tool in Brønsted Acid Catalysis
}

\author{
Polyssena Renzi, Johnny Hioe, and Ruth M. Gschwind*(i) \\ Institut für Organische Chemie, Universität Regensburg, D-93040 Regensburg, Germany
}

Supporting Information

\begin{abstract}
Despite the wide applicability of enantioselective Brønsted acid catalysis, experimental insight into transition states is very rare, and most of the mechanistic knowledge is gained by theoretical calculations. Here, we present an alternative approach (decrypting transition state by light = DTS- $h \nu$ ), which enables the decryption of the transition states involved in chiral phosphoric acids catalyzed addition of nucleophiles to imines. Photoisomerization of double bonds is employed as a mechanistic tool. For this class of reactions four pathways (Type I Z, Type I E, Type II Z, Type II E) are possible, leading to different enantiomers depending on the imine configuration (E- or Z-imine) and on the nucleophilic

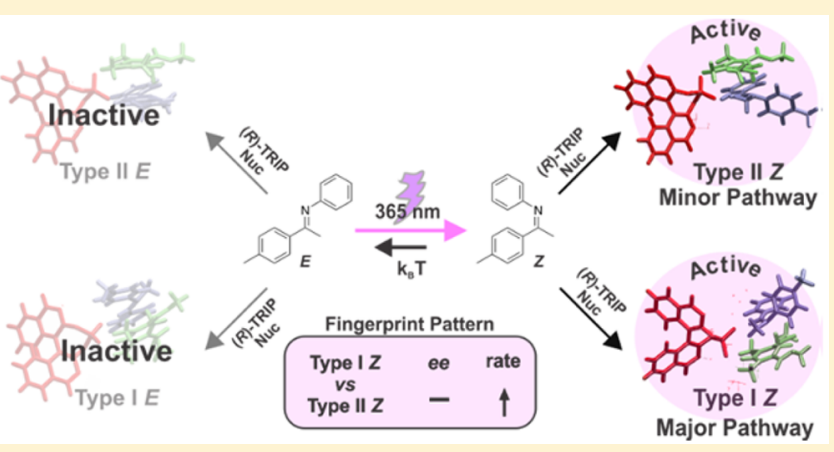
attack site (top or bottom). We demonstrated that the imine double bond can be isomerized by light ( $365 \mathrm{~nm}$ LED) during the reaction leading to a characteristic fingerprint pattern of changes in reaction rate and enantioselectivity. This characteristic fingerprint pattern is directly correlated to the transition states involved in the transformation. Type I $Z$ and Type II $Z$ are demonstrated to be the competing pathways for the asymmetric transfer hydrogenation of ketimines, while in the nucleophilic addition of acetylacetone to $\mathrm{N}$-Boc protected aldimines Type I $E$ and Type II $E$ are active. Accelerations on reaction rate up to $177 \%$ were observed for ketimines reduction. Our experimental findings are supported by quantum chemical calculations and noncovalent interaction analysis.
\end{abstract}

\section{INTRODUCTION}

Chiral phosphoric acids represent an attractive and widely applicable class of enantioselective organocatalysts in terms of different activation modes. ${ }^{1-8}$ The pioneering work of Akiyama ${ }^{9}$ and Terada, ${ }^{10}$ which introduced these compounds in the role of catalysts, set the fundament for the further development of Brønsted acid catalysis. Nowadays, the more than 400 asymmetric transformations published in this area prove the power and the broad applicability of this class of compounds. Despite the high performance of chiral phosphoric acids in terms of yields and enantioselectivity, structural and experimental mechanistic studies are very rare, and most of the insight is provided by theoretical calculations. ${ }^{11-17}$

In the context of our work on the NMR mechanistic investigation on phosphoric acids catalyzed addition of nucleophiles to imines, we sought an alternative method to gain insight into the reaction mechanism. We questioned whether Brønsted acid catalysis and photoisomerization of double bonds might be successfully merged to provide an experimental platform to access the transition states (TS) involved in these transformations. If an isomerization of the imine double bond is active during the reaction, it would be possible to exploit the photoisomerization as a mechanistic tool (Figure 1). We proposed, in fact, that changes in rate and enantiomeric excess upon illumination create a characteristic fingerprint pattern, which is associated with a particular transition state (Figure 2).

A huge contribution in terms of mechanistic studies in this field was given by Goodman ${ }^{11-14}$ and Himo, ${ }^{15}$ but a direct experimental proof of the reaction mechanism is still not available. According to these studies, ${ }^{11,12,14,15}$ ternary complexes are postulated as active transition states. Since the imine can adopt an $E$ - or Z-configuration and the nucleophilic attack can occur from the top or the bottom of the imine/catalyst binary complex, four different stereochemical arrangements in the transition state, denominated as Type I Z, Type I E, Type II $Z$, Type II E (Type I = bottom attack; Type II = top attack), are possible (Figure 2a). For a distinct chiral phosphoric acid, the preference for one pathway is determined by the nucleophile type, the size of imine substituents (Figure 2, $\mathrm{R}_{1}$ and $R_{2}$ ) and its configuration $(E$ or $Z) .{ }^{12,14}$ Moreover in the previous studies, a fast isomerization of the imine double bond is assumed, thus the reaction occurs through the lowest transition state. ${ }^{11,12,14,15}$ Our recent NMR structural characterization of imine/(R)-TRIP binary complexes disclosed four different structures, ${ }^{16}$ which can be regarded as precursors of the transition state models of Goodman (Type I $Z$, Type I E, Type II Z, Type II E). However, deviating from the models

Received: March 22, 2017

Published: May 4, 2017 


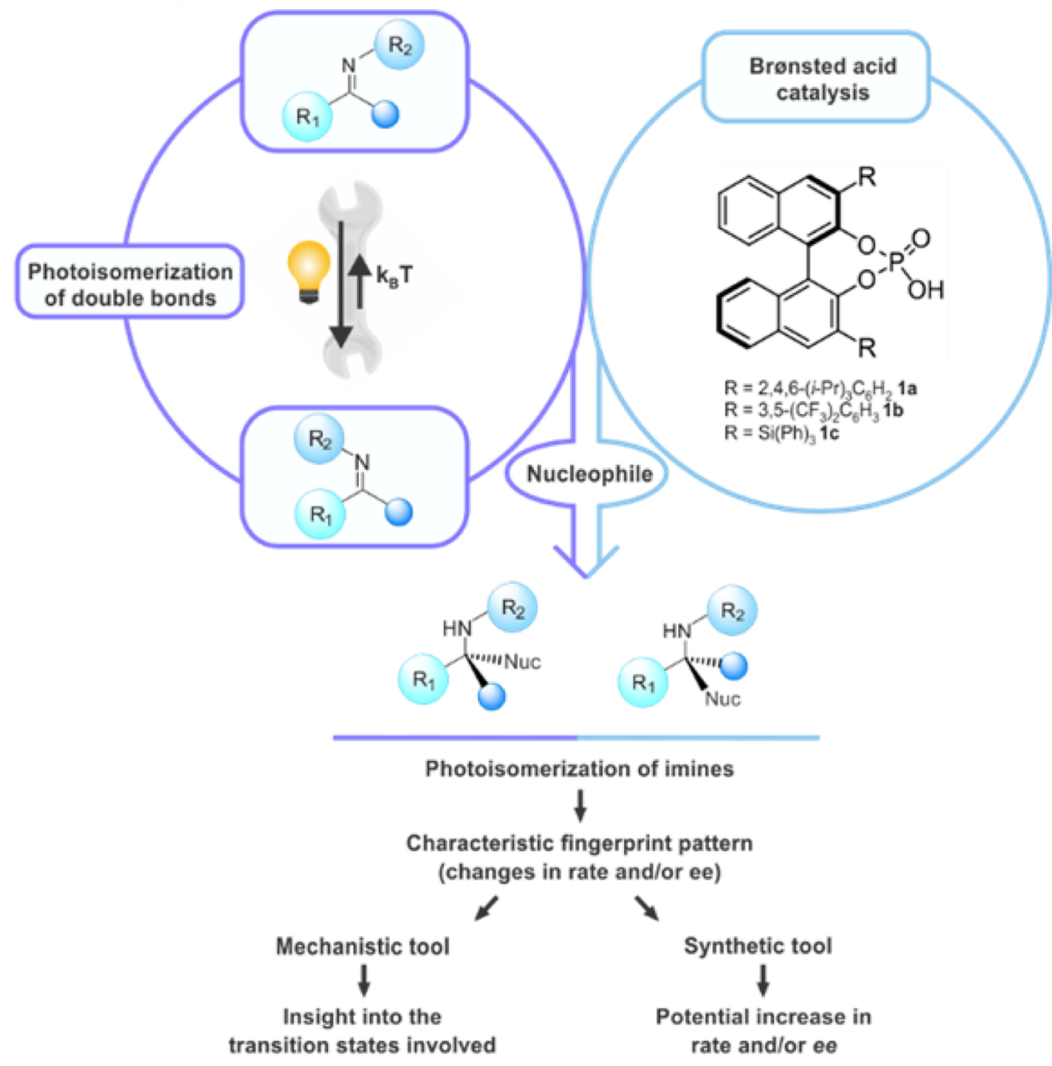

Figure 1. Merging Brønsted acid catalysis with photoisomerization of double bonds: experimental access to active transition states and potential optimization of catalysis.

proposed so far, we found experimentally that the $E / Z$ isomerization within these binary complexes is slow on the NMR time scale. Additionally, only low concentrations of the $Z$-imine in the binary complexes with TRIP 1a were detected. ${ }^{17,18}$ Given the fact that photochemical processes offer the possibility for an effective isomerization of double bonds, ${ }^{19-26}$ we developed an experimental, easily applicable method, which employs photoisomerization as a mechanistic tool. In the following, this method will be referred to as DTS$h \nu$ (decrypting transition states by light), since the photoisomerization allows us to decrypt, i.e., to change the experimentally nonobservable transition states back into easily readable data sets including reaction rates and enantioselectivity. The changes in reaction rate and enantiomeric excess values obtained upon in situ illumination are, in fact, directly connected to the TS involved in BINOL-derived phosphoric acids catalyzed reactions generating a characteristic fingerprint like pattern (Figure $2 b$ ). Furthermore, it has the potential to improve synthetic applications. For the applicability of our DTS- $h \nu$ approach, the reaction under consideration has to fulfill three mechanistic conditions: (i) the double bond can be photoisomerized without significant photodegradation; (ii) no change in the principal reaction mechanism is observed upon irradiation, i.e., no background reaction is active, thus the illumination affects only the E/Z-ratio; (iii) the double bond isomerization has to be slow or comparable to the enantioselective step, i.e., the overall rate is affected by the change in the concentration of the $E$ and $Z$ isomers. Reactions, which comply with these requirements, respond differently to illumination depending on the active transition states involved in the formation of the two product enantiomers (Figure $2 b$ ). Considering the four proposed transition states (Figure 2a) and that an imine can be isomerized from the $E$ to $Z$ isomer by means of light, ${ }^{22,27,28}$ four different scenarios are possible (Figure $2 \mathrm{~b}$ ) upon competition of two transition states. When the product formation proceeds via Type I $Z$ and Type II $Z$ transitions states (Figure $2 \mathrm{~b}$, Scenario 2 ) the photoisomerization, which converts the $E$-imine present in solution partially to the $Z$-form, should result in the increase of reaction rate without any change on the enantioselectivity. On the contrary, when Type I $E$ and Type II $E$ transition states are involved (Figure 2b, Scenario 4), the light induced isomerization will reduce the reaction rate without affecting the enantiomeric excess. When both $E$ and $Z$-transition states are active, not only mechanistic insights and change on reaction rate are possible, but also a modulation of the enantioselectivity can be achieved. In the case the light driven isomerization supports the isomer producing the major enantiomer, improvement of synthetic application is possible since the reaction would show both acceleration and increase of the enantiomeric excess (Figure $2 b$, Scenario 3), the gold standard in stereoselective synthesis. Vice versa, when the $E$-imine is the precursor of the major product and its concentration is reduced by the light, a detrimental effect would be obtained for both reaction rate and enantioselectivity (Figure 2b, Scenario 1). ${ }^{29}$

\section{RESULTS AND DISCUSSION}

To test the applicability of the DTS- $h \nu$ approach the asymmetric transfer hydrogenation of ketimines $\mathbf{2 a - i}$, developed independently by List and Rueping, ${ }^{30-32}$ was chosen as model reaction. The necessary mechanistic conditions were fully satisfied. As reported in literature imines isomerization occurs photoinduced or via thermal processes. Works on this 
a)

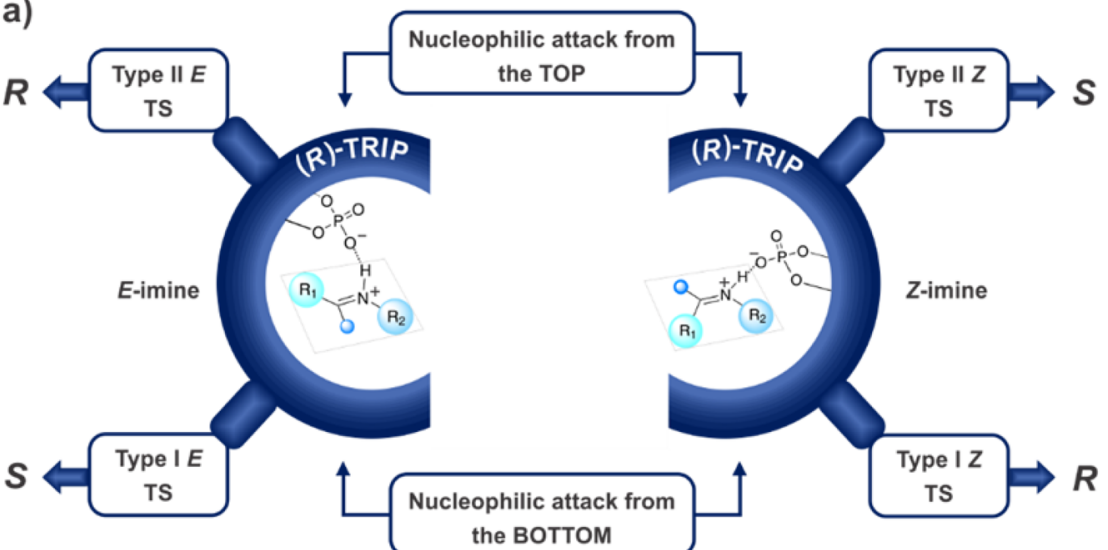

b)

Minor product

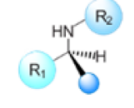

$S$ the воттом

Major product

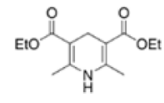

Nuc

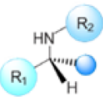

$\boldsymbol{R}$

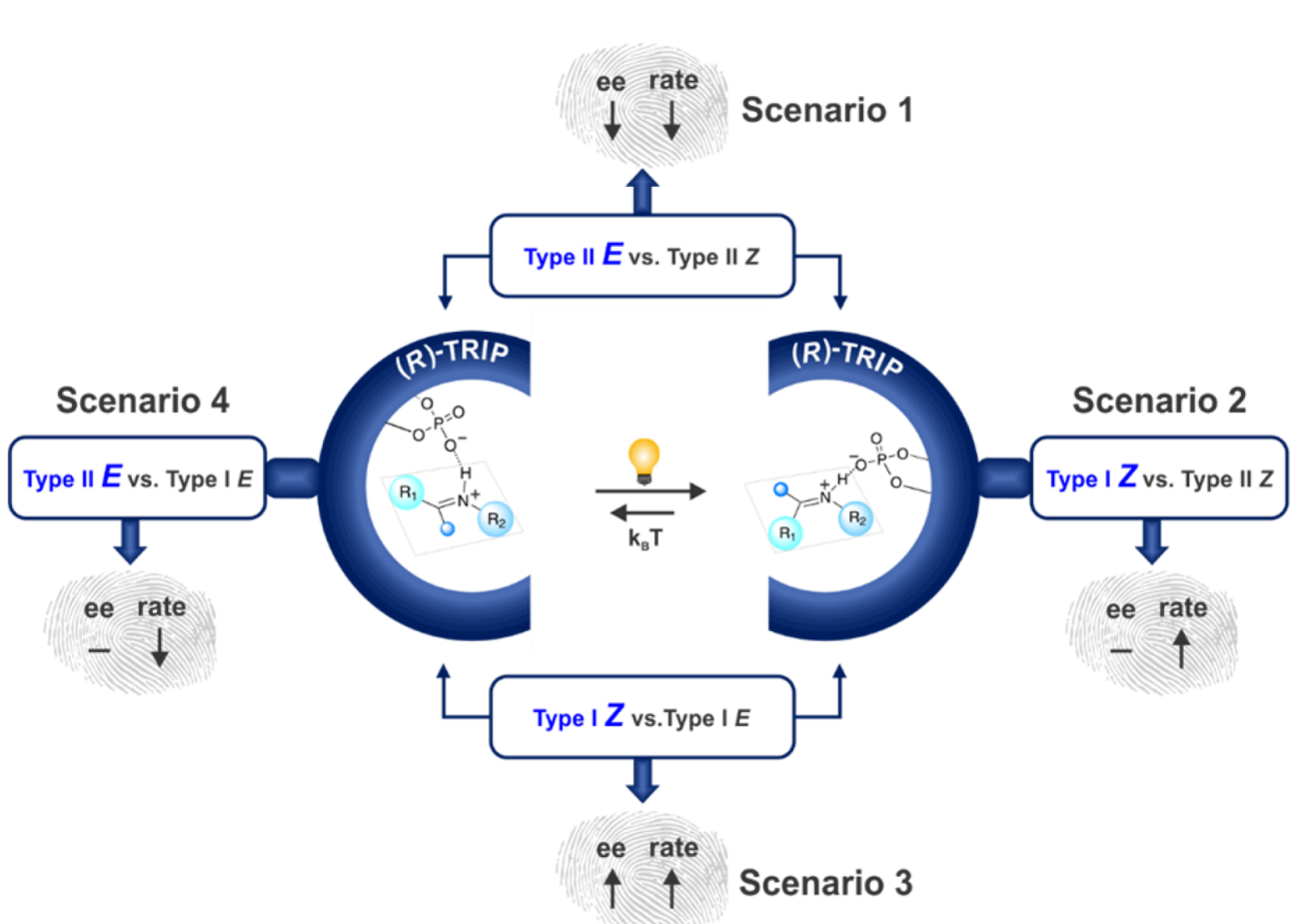

Figure 2. Transition states and produced fingerprint pattern upon photoisomerization for phosphoric acids catalyzed addition of nucleophiles to imines: (a) Transition states proposed for the transfer hydrogenation of imines in the presence of Hantzsch ester analogue to Goodman's. ${ }^{14}$ The example shows that four pathways (Type I $Z$, Type I $E$, Type II $Z$, Type II $E$ ) lead to different enantiomers depending on the imine configuration ( $E$ or $Z$-imine) and on the nucleophilic attack site (top or bottom). $R$ and $S$ refer to the stereogenic center configuration in the product. (b) Changes in characteristic fingerprint pattern (rate and enantiomeric excess $(e e)$ ) upon illumination given the competition of two transition states. In case the major enantiomer is $R$ only 4 out of 8 transition state combinations can be active (the transition states labeled in blue correspond to the major pathway in operation in case of $(R)$-configured major product; for a complete set of scenarios see the SI). $\uparrow$ increase in ee or reaction rate; $\downarrow$ decrease in $e e$ or reaction rate; - no change in $e e$; $(R)$-TRIP 1a $\left((R)-3,3^{\prime}\right.$-Bis (2,4,6-triisopropylphenyl)-1,1'-binaphthyl-2,2'-diyl hydrogen phosphate).

subject were described by Fisher long time ago employing low temperature NMR measurement and external illumination with a mercury lamp. ${ }^{27}$ Applying the LED based NMR illumination device developed in our group, ${ }^{33}$ we explored the feasibility of ketimines $\mathbf{2 a - i}$ isomerization by in situ irradiation of the NMR sample by using a glass fiber coupled with a $365 \mathrm{~nm}$ LED. It was possible, in this way, to follow the isomerization by recording ${ }^{1} \mathrm{H}$ NMR spectra with regular intervals of time while the sample was subjected to a continuous illumination at $180 \mathrm{~K}$. Low temperature measurements were necessary in order to prevent thermal back reaction and allow for $Z$-imine characterization. As an example, sections of imine $2 a^{1} \mathrm{H}$ NMR spectra are shown in Figure 3. The imine can be isomerized both as a single component (Figure 3a; an E-imine 2a solution was 

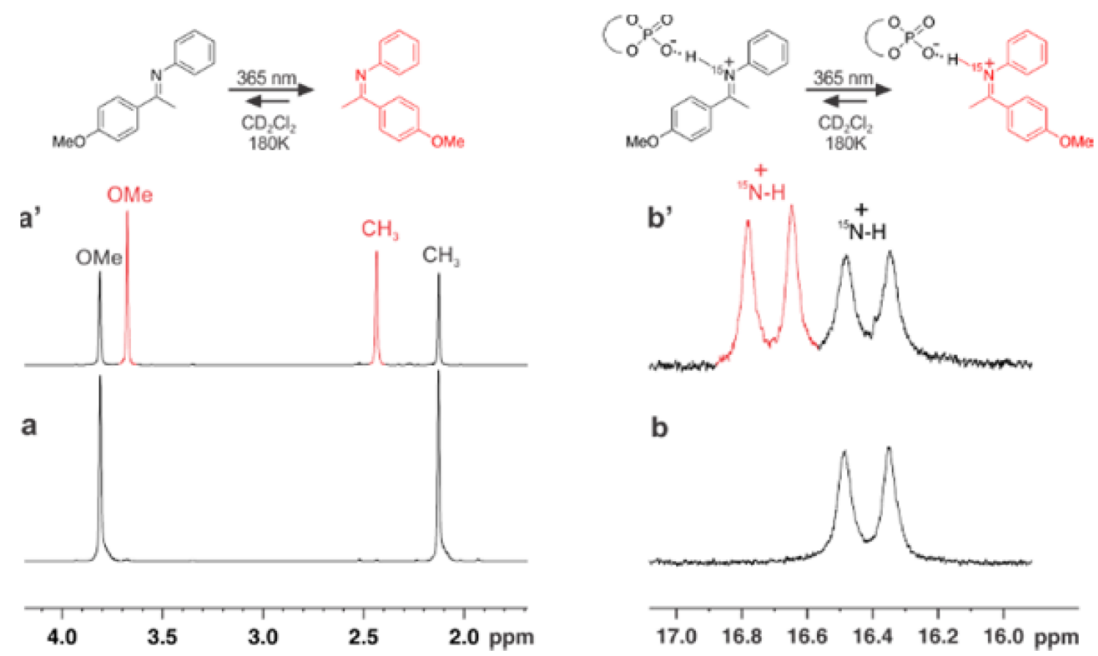

Figure 3. In situ NMR photoinduced isomerization of model imine 2a and its TRIP-complexes. (a) The Me- and OMe- sections of ${ }^{1} \mathrm{H}$ NMR spectra of imine $2 \mathrm{a}$ in $\mathrm{CD}_{2} \mathrm{Cl}_{2}$ at $180 \mathrm{~K}(600 \mathrm{MHz})$ in the dark and after 90 min illumination (photostationary state) show the effective isomerization from $E$ to $Z$ of free imine 2a. (b) Low field sections of ${ }^{1} \mathrm{H}$ NMR spectra of an imine $2 \mathrm{a} /(R)$-TRIP 1a binary complex in $\mathrm{CD}_{2} \mathrm{Cl}_{2}$ at $180 \mathrm{~K}(600 \mathrm{MHz})$ showing the characteristic signals of the ${ }^{15} \mathrm{~N}-\mathrm{H}$ in the hydrogen bond in the dark and after 90 min illumination (photostationary state). The spectra clearly shows that the imine photoisomerization is also possible inside the binary complex.

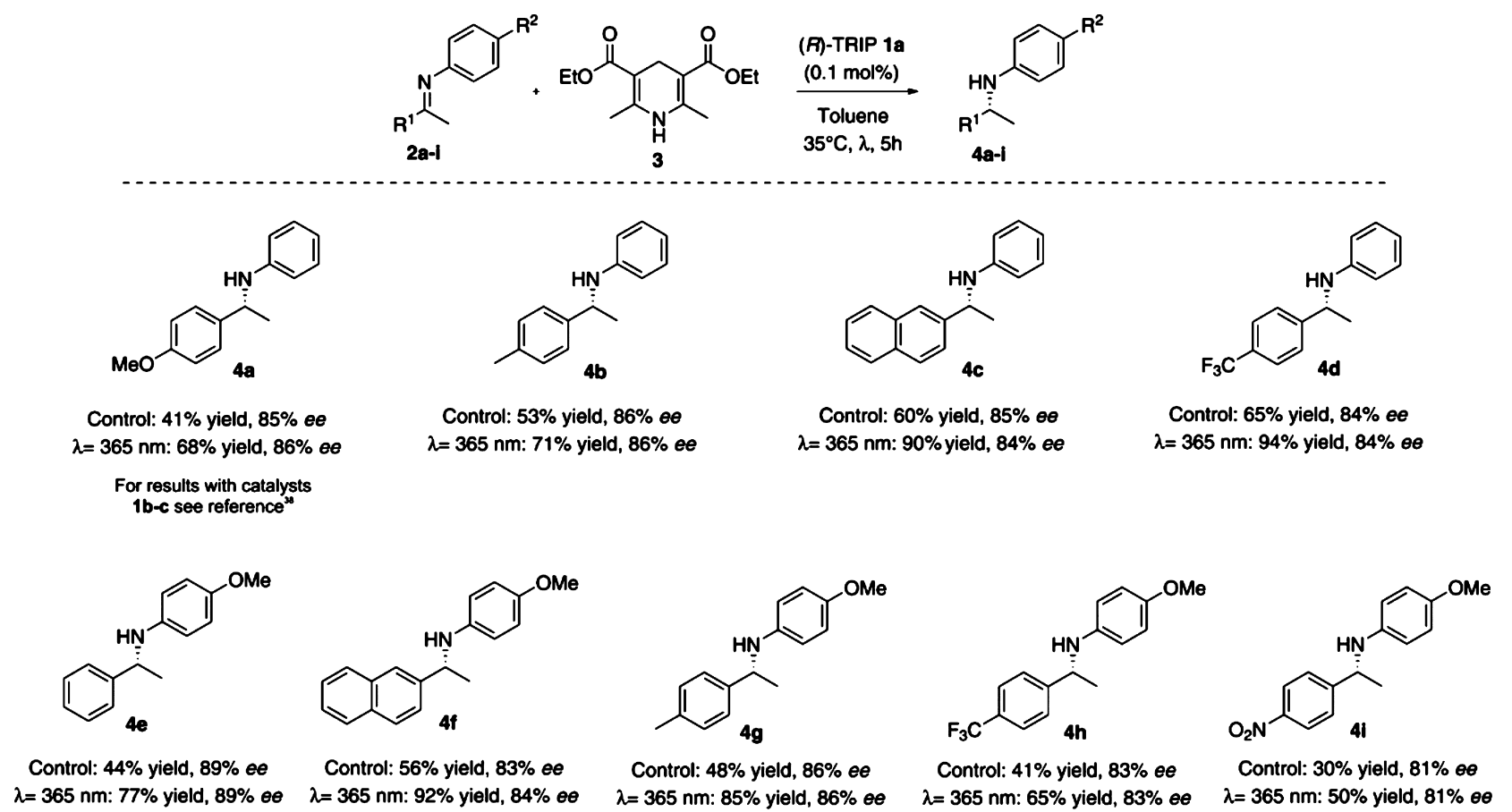

Figure 4. Effect of light on the asymmetric hydrogenation: screening of imines $\mathbf{2 a}-\mathbf{i}$. All reactions were carried out employing imine $\mathbf{2 a}-\mathbf{i}(0.36$ mmol, 1 equiv), Hantzsch ester 3 (1.4 equiv) and (R)-TRIP 1a (0.01 equiv) in $4.4 \mathrm{~mL}$ toluene under continuous illumination with a $365 \mathrm{~nm}$ LED lamp for $5 \mathrm{~h}$ at $35^{\circ} \mathrm{C}$. The control reactions were run in the same conditions without LED illumination. Isolated yield after chromatography are shown. The ee values were determined by HPLC on chiral stationary phase; changes on ee are within the experimental error.

subjected to $90 \mathrm{~min}$ of irradiation with a $365 \mathrm{~nm}$ LED in $\mathrm{CD}_{2} \mathrm{Cl}_{2}$ at $180 \mathrm{~K}$, the $\mathrm{E} / \mathrm{Z}$-imine ratio obtained was 1 to 1.6 ) and inside the binary complex formed with the chiral phosphoric acid (Figure 3b; a 1:1 mixture of E-imine 2a and (R)-TRIP 1a was subjected to $90 \mathrm{~min}$ of irradiation with a 365 $\mathrm{nm} \mathrm{LED}$ in $\mathrm{CD}_{2} \mathrm{Cl}_{2}$ at $180 \mathrm{~K}$, the obtained $\mathrm{E} / Z$-ratio in the binary complex was 1 to 1$)$. No conformational change was observed under blue or green light in agreement with the imine $\mathrm{UV}$ absorption spectrum $\left(\lambda_{\max } 2 \mathrm{a}=268 \mathrm{~nm}\right)$. No byproducts of photoinduced decomposition were detected after $24 \mathrm{~h}$ of continuous irradiation of the samples. Deuterated dichloro- methane was chosen as solvent since a better line-width can be obtained for the imine/catalyst binary complexes NMR spectra, as reported in our previous studies. ${ }^{16,17} \mathrm{~A}$ reduced isomerization rate was observed in toluene- $d_{8}$ (E-imine 2a, $90 \mathrm{~min}$ irradiation with the $365 \mathrm{~nm}$ LED in toluene- $d_{8}$ at $180 \mathrm{~K}$ gave a mixture of $E / Z$-imines with a 1 to 0.3 ratio).

The other requirement that has to be met is that the background reaction is not active thus the illumination affects only the E/Z-ratio. Two different experiments were performed to prove this point. It is known in literature, that imines, in particular aldimines, can be photoreduced without any 


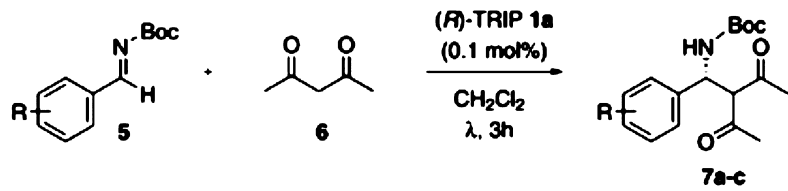

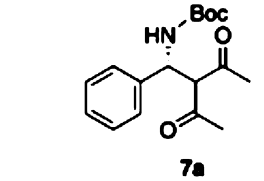

Control: $73 \%$ yiold, $89 \%$ $\lambda=365 \mathrm{~nm}: 50 \%$ yield. $89 \%$

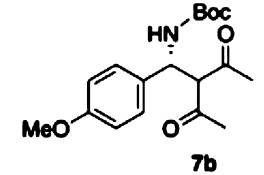

Control: $85 \%$ yield, $86 \% 00$ $\lambda=365 \mathrm{~nm}: 50 \%$ yield, $86 \%$

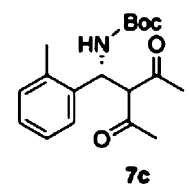

Control: $70 \%$ yield. $92 \%$ or

$\lambda=365 \mathrm{~nm}$ : $43 \%$ yield, $92 \%$

Figure 5. Effect of light on the nucleophilic addition of acetylacetone 6 to aldimines $5 \mathbf{a}-\mathbf{c}$. All reactions were carried out employing aldimines $5 \mathrm{a}-\mathrm{c}$ $(0.23 \mathrm{mmol}, 1$ equiv), acetylacetone 6 (1.1 equiv) and $(R)$-TRIP 1a (0.1 equiv) in $2.3 \mathrm{~mL}$ dichloromethane under continuous illumination with a $365 \mathrm{~nm}$ LED lamp for $3 \mathrm{~h}$ at room temperature. The control reactions were run in the same conditions without LED illumination. Isolated yield after chromatography are shown. The ee values were determined by HPLC on chiral stationary phase.

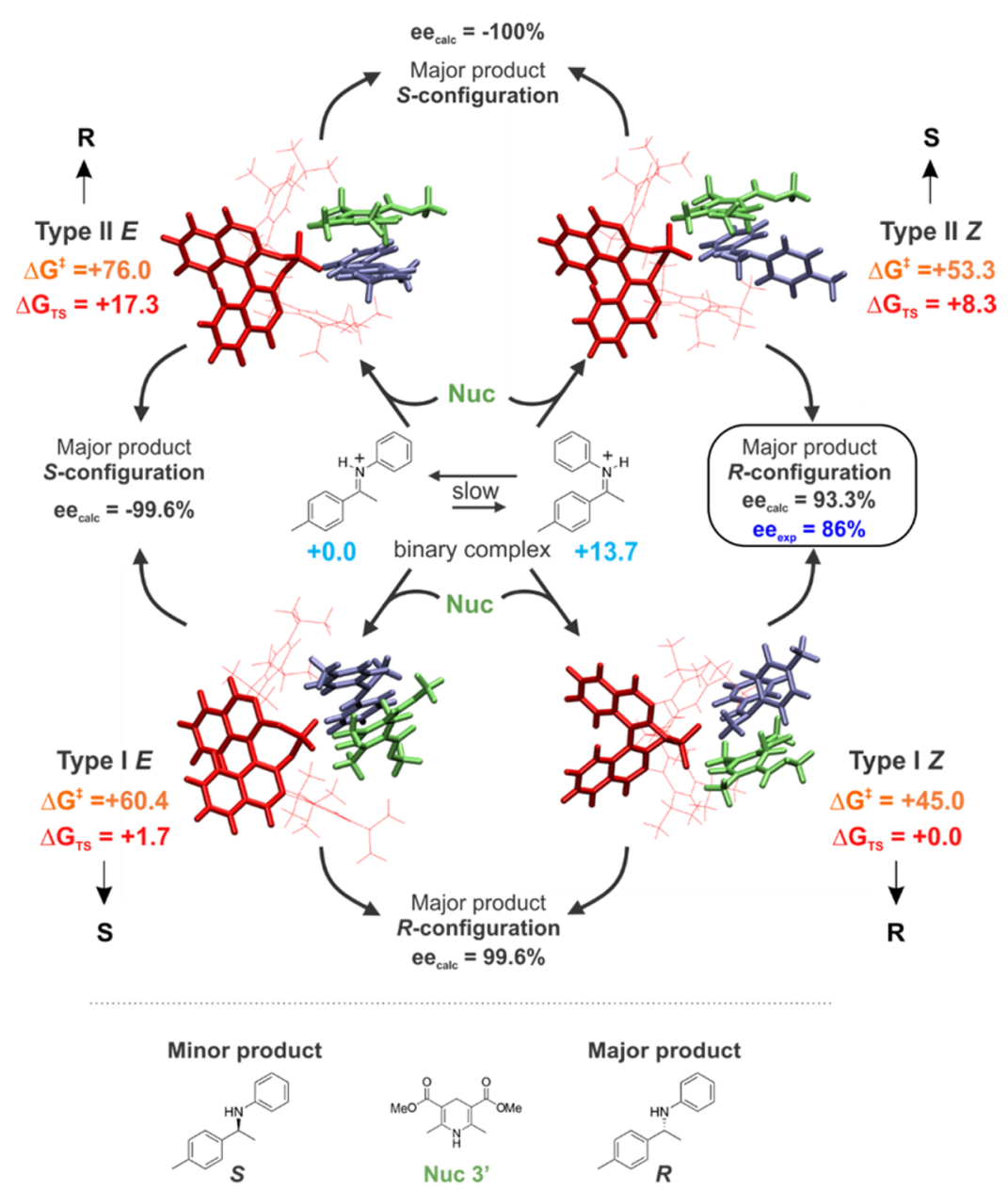

Figure 6. Type I/II $E / Z$ transition states for the transfer hydrogenation reaction of imine $\mathbf{2} \mathbf{b}$ using Hanztsch ester model $\mathbf{3}^{\prime}$. The pathways following Type I/II $Z$ possess the lowest barrier, which is in agreement with the illumination experiment. Red colored structures: (R)-TRIP 1a. Blue colored structures: ketimine $\mathbf{2 b}$. Green colored structures: Hanztsch ester model $\mathbf{3}^{\prime}$. Numbers in light blue: thermodynamic difference between $E$-imine $\mathbf{2 b}$ / (R)-TRIP 1a and Z-imine $2 \mathrm{~b} /(\mathrm{R})$-TRIP 1a. Numbers in red: $\Delta G_{\mathrm{TS}}$ of the transition states. Numbers in orange: absolute barrier height $\Delta G^{\ddagger}$. All energies are given in unit $\mathrm{kJ} / \mathrm{mol}^{43}$

asymmetric induction in the presence of dihydropyridine Hantzsch esters 3 in benzene or of a ketone as photosensitizer in a protic solvent under illumination with a medium pressure mercury lamp. ${ }^{34-37}$ In our case, employing toluene as solvent no product or byproduct formation could be detected when imine $\mathbf{2 a}$ and Hantzsch ester 3 were irradiated with the $365 \mathrm{~nm}$
LED for $24 \mathrm{~h}$. The reduction under illumination was observed only in the presence of catalyst $\mathbf{1 a}$.

The second experiment was performed to prove that the light is affecting only the imine isomerization and it has no effects on the enantioselective step, i.e., the hydride transfer from the Hantzsch ester 3. To prove our assumption, we 
decided to test the reaction on a nonisomerizable imine in the way a change on reaction rate should be obtained only if the hydride transfer is affected by the light. Employing $\mathrm{N}$ (diphenylmethylene)benzenamine as nonisomerizable starting material no significant change on the reaction outcome was detected, so the influence of light on the hydride transfer could be excluded (control reaction 37\% yield; $365 \mathrm{~nm}$ LED illumination $35 \%$ yield). With all the mechanistic conditions met, we first examined the effect of light on the hydrogenation of imine 2a, with Hantzsch ester $\mathbf{3}$ as hydride donor, employing (R)-TRIP 1a as catalyst. The reaction conditions previously described by List were employed. ${ }^{30}$ To our delight, with respect to a control reaction run without illumination, we observed after continuous irradiation with a $365 \mathrm{~nm}$ LED a significant increase on reaction rate without any change on the enantiomeric excess (Figure 4, product 4a). Comparing these results with the changes in the characteristic fingerprint pattern (rate and ee) upon illumination proposed in our method (Figure $2 b$ ), this reaction proceeds according to Scenario 2, i.e., via Type I $Z$ and Type II $Z$ transitions states. This means that the E-imine did not participate in the product formation and an active isomerization of the double bond should be operated by the catalyst in absence of light. When the system is irradiated with the right wavelength, the amount of $Z$-isomer can be enhanced causing the increase on reaction rate. Two Ztransition states are competing. Since an $R$ configured product $\mathbf{4 a}$ is formed employing (R)-TRIP 1a, as shown in Figure 2a, Type I $Z$ should be the major pathway followed, thus the nucleophilic attack occurs from the bottom of the binary complex. Different phosphoric acid catalysts $\mathbf{1} \mathbf{b}-\mathbf{c}$ were tested together with imine $\mathbf{2 a}$ observing in all cases the same change in the characteristic fingerprint pattern (no change in $e e$, increase in reaction rate). ${ }^{38}$ In dichloromethane, which was the solvent of choice for the isomerization study, catalyst la gave lower yield and ee than in toluene (30\% yield, $70 \%$ ee for the control reaction after $5 \mathrm{~h}$ in dichloromethane). ${ }^{39}$ Therefore, toluene, as described by List, ${ }^{30}$ was chosen as the solvent to continue our investigation. Our method was then tested on ketimines $\mathbf{2 b}-\mathbf{i}$ (Figure 4). For all the imines screened, first, the photoisomerization was studied by NMR at low temperature in $\mathrm{CD}_{2} \mathrm{Cl}_{2}$, then the illumination was carried out in the reaction conditions applied to compound 2a. Figure 4 summarizes the results obtained in terms of yield and enantioselectivity for the control reaction and under illumination. For all compounds belonging to the family of ketimines $\mathbf{2 a}-\mathbf{i}$, the illumination affects the reaction in the same way. A significant increase in reaction rate is observed (134-177\% increase of yields after $5 \mathrm{~h}$ considering the yield of control reactions as reference value) with no change in enantiomeric excess with respect to the control. Scenario 2 of our method is followed proving experimentally that the hydride transfer hydrogenation of ketimines catalyzed by chiral phosphoric acids proceeds via Type I $Z$ and Type II $Z$ transitions states. Having established our proposal, we focused our attention to prove the generality of the DTS- $h \nu$ method. Type I $E$ is postulated to be the active transition state in phosphoric acid catalyzed reactions involving aldimines and small symmetric nucleophiles. ${ }^{11,12}$

To prove the effective involvement of Type $E$ transition states for aldimines, we applied our method to the nucleophilic addition of acetylacetone 6 to $\mathrm{N}$-Boc protected imines $5 \mathrm{a}-\mathrm{c}$ employing, also in this case, (R)-TRIP 1a as catalyst. ${ }^{10}$ For all the three compounds tested $\mathbf{5 a}-\mathbf{c}$, we observed upon illumination a significant reduction on reaction rate and no effect on the enantioselectivity with respect to the control reaction (Figure 5). According to these results, Scenario 4 (Figure $2 \mathrm{~b}$ ) is fully met for aldimine $\mathbf{5}$ reactions. Type I $E$ and Type II $E$ are both involved. When the $E$-aldimine is converted by isomerization to the $Z$-form, the amount of product precursors is reduced causing, in this way, a drop in reaction rates.

To confirm the two active transition states proposed by the photoisomerization experiment for ketimines (Type I $Z$ and Type II Z), quantum chemical calculations of the transition states and the ground states of the binary complex for ketimine 2b hydrogenation were performed. For the calculations we chose $p$-Me-ketimine $\mathbf{2 b},(R)$-TRIP $\mathbf{1 a}$ as catalyst and a reduced model of Hantzsch ester $3^{\prime}$ as nucleophile (Figure 6). ${ }^{40-42}$ Despite of the presence and the bulkiness of the 3,3'substituents on the Brønsted acid catalyst 1a, the nucleophile, i.e., Hanztsch ester $3^{\prime}$, can still approach from two sites, e.g., bottom and top (Figure 2a,b and Figure 6). Depending on the configuration of the imine, the top and the bottom attack will produce respectively the $R$ - and the $S$-product. All together, we found four transition states leading to the different product enantiomers, which are comparable with previous computational studies by Goodman. ${ }^{11,12,14}$ In the case of our model reaction, the lowest transition state was also found for the nucleophilic attack to the $Z$-imine from the bottom side (Type I $Z$ ). The second lowest transition state was located marginally above the Type I $Z$ TS and was calculated for the bottom attack to the E-imine $(+1.7 \mathrm{~kJ} / \mathrm{mol}$, Type I E). The third TS corresponds to the top attack to the $Z$-imine $(+8.3 \mathrm{~kJ} / \mathrm{mol}$, Type II $Z$ ) and the highest transition state was predicted for the top attack to the $E$-imine $(+17.3 \mathrm{~kJ} / \mathrm{mol}$; Type II E). The order of the stability of the transition states is qualitatively identical with the previous computational study, which also showed that the transition state Type I $Z$ is energetically favored, followed by Type I $E .^{11,12,14}$ Assuming a fast equilibrium between $E / Z$ isomers in the binary complex (Curtin-Hammett) as applied previously, the major product would be correctly the $R$ enantiomer.

However, according to the small energetic difference of 1.7 $\mathrm{kJ} / \mathrm{mol}$ between Type I $Z$ and Type I E, a low enantiomeric excess of $30 \%$ ee is calculated. This value deviates more than $56 \%$ from the experimental value $(86 \% e e)$. The effect observed from our photoisomerization experiment on the reaction rate clearly showed that the isomerization between $E$ - and $Z$-imine is slower than the enantioselective step. This means that the thermodynamic of the ground state binary complex between $E$ and $Z$ has to be taken into account for the calculations of the barriers. Consequently, the paths following the Type I $Z$ and Type II $Z$ are the two energetically least demanding and hence active in the product formation. The calculated enantiomeric excess value from the barrier height difference between Type I $Z$ and Type II $Z$ amounts to $93 \%$ ee, which is quite close to the found experimental value of $86 \%$ ee. This is further confirmed by our photoisomerization experiment (Scenario 2 in Figure $2 \mathrm{~b}$ : increase in rate but no change in $e e$ values), proving that the $E$-imine did not participate in the product formation, and the two $Z$-transition states are competing. ${ }^{42}$

The competition between these transition states is additionally supported by the structural and the noncovalent interaction (NCI) analysis of the hydrogen bonded systems (for a basic explanation of NCI analysis see SI). ${ }^{44,45}$ The structural analysis of the transition states revealed that the $\mathrm{O}-\mathrm{H}$ distance within the hydrogen bond between the imine and the catalyst (Figure 
a) Type IE
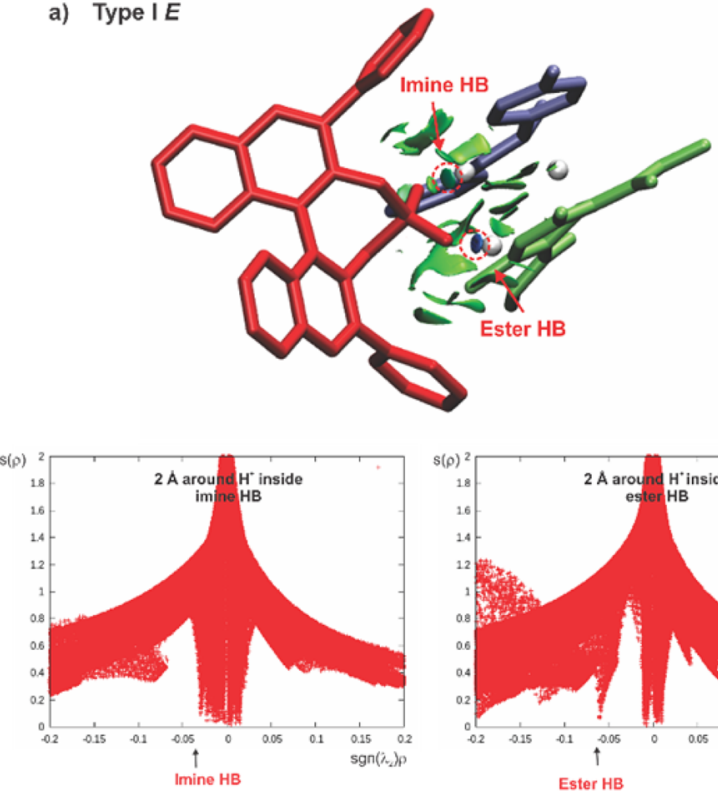

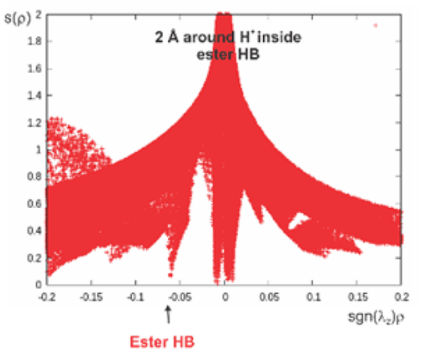

b) Type I Z

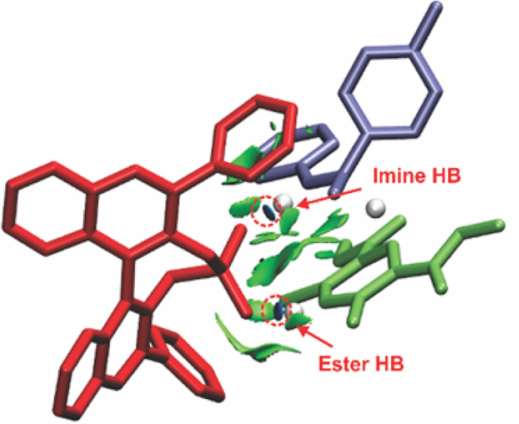

Figure 7. NCI plot and plots of reduced density gradient $\mathrm{s}(\rho)$ vs electron density multiplied by the sign of the second Hessian eigenvalue sgn $\left(\lambda_{2}\right) \rho$ of the transition states of Type I $E(a)$, and Type I $Z(b)$. The hydrogen bond in Type I $E$ is weakened allowing the imine to avoid steric repulsion with the 3,3'-substituent of the catalyst. The region of $2.0 \AA$ around the hydrogen atom in the hydrogen bond (imine HB and ester HB) are shown. The hydrogens and isopropyl groups are omitted for the sake of clarity. Green colored: Hanztsch ester $3^{\prime}$, red colored: (R)-TRIP 1a, and blue colored: imine $\mathbf{2 b}$. The chosen isovalue is 0.4 , and the color range is -7.0 to 7.0. The Type I $E$ exhibits weaker hydrogen bond (greenish colored surface for the imine $\mathrm{HB}$ and larger $\operatorname{sgn}\left(\lambda_{2}\right) \rho$ ) compared to the Type I $Z$.

7; imine $\mathrm{HB}$ ) is significantly elongated compared to the ground state binary complexes $\left(\mathrm{d}(\mathrm{O}-\mathrm{H})_{\text {imine/catalystT }}=164-188 \mathrm{pm}\right.$; $\left.\mathrm{d}(\mathrm{O}-\mathrm{H})_{\text {imine } / \text { catalystGS }}=138-149 \mathrm{pm}\right) .{ }^{17}$ In contrast, the hydrogen bond between the ester and the catalyst (Figure 7; ester $\mathrm{HB})$ is the shortest in the transition state complex $(\mathrm{d}(\mathrm{O}-$ $\left.\mathrm{H})_{\text {ester/catalystTS }}=159-164 \mathrm{pm}\right)$, which was already proposed previously. ${ }^{15}$ Thus, the hydrogen bond between the imine and the catalyst is weakened upon binding of the Hanztsch ester facilitating the transfer of the hydride to the imine. This is corroborated by the NCI analysis of the ground ${ }^{16}$ and transition states showing more negative $\operatorname{sgn}\left(\lambda_{2}\right) \rho$ values for the ground state. The fact that the ester $\mathrm{HB}$ is stronger than the imine HB is also reflected in the NCI plot by showing more negative $\operatorname{sgn}\left(\lambda_{2}\right) \rho$ values for the ester $\mathrm{HB}\left(\operatorname{sgn}\left(\lambda_{2}\right) \rho=-0.03\right.$ to -0.05 for imine $\mathrm{HB} ; \operatorname{sgn}\left(\lambda_{2}\right) \rho=-0.06$ for ester $\left.\mathrm{HB}\right)$.

Moreover, a comparison between the $E$ - and $Z$-transition states showed that the $\mathrm{O}-\mathrm{H}_{\text {imine/catalystTs }}$ bond is much longer in the $E$-transition states $(185-188 \mathrm{pm})$ than in the $Z$-transition states (164-172 pm) indicating a weaker hydrogen bond in Type I E. As evidenced by the NCI analysis, the critical point $(\mathrm{s}(\rho)=0)$ of the imine HB in Type I $E$ is located at $\operatorname{sgn}\left(\lambda_{2}\right) \rho \approx$ -0.03 , while in Type I $Z$ it is calculated at $\operatorname{sgn}\left(\lambda_{2}\right) \rho \approx-0.05$. Previously, the steric repulsion due to the $3,3^{\prime}$-substituent of the catalyst was proposed to be the possible reason for the destabilization of the E-configured TS. ${ }^{12,15}$ However, our NCI analysis showed that the 3,3'-substituents of TRIP in the transition states do not exhibit a strong repulsive interaction with the imine but rather a communication via weak attractive van der Waals interactions is established (see Figure S14 in Supporting Information for the NCI-plot). All together the NCI analysis and structural analysis showed that the destabilization of the $E$-transition state is due to the structural adaptation of the transition states: the hydrogen bond between imine and phosphoric acid is elongated and weakened. This allows for the interconversion of repulsive into attractive interactions between the $3,3^{\prime}$-substituents of catalyst $1 \mathbf{a}$ and the imine.

\section{CONCLUSIONS}

In summary, the DTS-h $\nu$ method provided the first experimental insight into Brønsted acid catalyzed reactions of imines. Photoisomerization of double bonds was exploited as a mechanistic tool to identify the active transition states. According to the scenarios proposed in Figure 2b, the detection of active transition states can be achieved by comparing the changes in reaction rate and enantiomeric excess values obtained after illumination with a dark control reaction. Two model systems were investigated. For the asymmetric transfer hydrogenation of imines $\mathbf{2} \mathbf{a}-\mathbf{i}$ the characteristic fingerprint pattern of changes obtained (increase on reaction rate, no change on enantioselectivity; Figure 2b, Scenario 2) upon illumination showed the competition between the two $Z$ transition states. According to the configuration of the major product $(R)-\mathbf{4 a}$, the nucleophilic attack to the $Z$-imine occurs from the bottom side (Type I $Z$ ). For the nucleophilic addition of acetylacetone 6 to $N$-Boc protected imines $5 \mathrm{a}-\mathrm{c}$, Type I $E$ and Type II $E$ were identified as the active transition states. The isomerization to the corresponding $Z$-imine is in fact detrimental for the reaction rate whereas the enantioselectivity was not affected (Figure 2b, Scenario 4). Our experimental results corroborate earlier computational predictions that the Type I $Z$ is the lowest transition state. ${ }^{11,15}$ Additionally, our combined experimental observations and quantum chemical calculations reveal that both ground state and transition state energetics have to be considered to select the active transition state combinations. Due to the slow isomerization between $E$ and $Z$-imine in the binary complex, the Curtin-Hammett principle does not apply. Hence, in the hydrogenation the 
ground state energy difference must be considered in the calculation of the energy barrier. The lowest barriers were predicted for pathways proceeding via Type I $Z$ and Type II $Z$ transition states. This was further rationalized by structural and NCI analysis, which showed a significantly weaker hydrogen bond between E-imine and catalyst 1a due to the steric property of the $3,3^{\prime}$-substituent of the compound 1a. The more flexible and compact structure of $Z$-imines allows these compounds to bind closer to the catalyst with respect to $E$ imines. A stronger hydrogen bond is formed which is essential for the stability of the TS.

\section{ASSOCIATED CONTENT}

\section{S Supporting Information}

The Supporting Information is available free of charge on the ACS Publications website at DOI: 10.1021/jacs.7b02539.

Full experimental procedures and characterization data (PDF)

\section{AUTHOR INFORMATION}

\section{Corresponding Author}

*ruth.gschwind@chemie.uni-regensburg.de

ORCID $\odot$

Ruth M. Gschwind: 0000-0003-3052-0077

Notes

The authors declare no competing financial interest.

\section{ACKNOWLEDGMENTS}

Financial support was provided by the European Research Council (ERC-CoG 614182, IonPairsAtCatalysis) and by the German Science Foundation (DFG, GRK 1626, Chemical Photocatalysis).

\section{REFERENCES}

(1) Akiyama, T. Synlett 2016, 27, 542-545.

(2) Parmar, D.; Sugiono, E.; Raja, S.; Rueping, M. Chem. Rev. 2014, 114, 9047-9153.

(3) Terada, M. Synthesis 2010, 12, 1929-1982.

(4) Kampen, D.; Reisinger, C. M.; List, B. Asymmetric Organocatalysis; Springer, 2010.

(5) Akiyama, T. Chem. Rev. 2007, 107, 5744-5758.

(6) Akiyama, T.; Itoh, J.; Fuchibe, K. Adv. Synth. Catal. 2006, 348, 999-1010.

(7) Connon, S. J. Angew. Chem., Int. Ed. 2006, 45, 3909-3912.

(8) Rueping, M.; Parmar, D.; Sugiono, E. Asymmetric Brønsted Acid Catalysis; Wiley-VCH: Weinheim, 2005.

(9) Akiyama, T.; Itoh, J.; Yokota, K.; Fuchibe, K. Angew. Chem., Int. Ed. 2004, 43, 1566-1568.

(10) Uraguchi, D.; Terada, M. J. Am. Chem. Soc. 2004, 126, 53565357.

(11) Simón, L.; Goodman, J. M. J. Am. Chem. Soc. 2008, 130, 87418747.

(12) Simón, L.; Goodman, J. M. J. Org. Chem. 2011, 76, 1775-1788.

(13) Overvoorde, L. M.; Grayson, M. N.; Luo, Y.; Goodman, J. M. J. Org. Chem. 2015, 80, 2634-2640.

(14) Reid, J. P.; Simón, L.; Goodman, J. M. Acc. Chem. Res. 2016, 49, 1029-1041.

(15) Marcelli, T.; Hammar, P.; Himo, F. Chem. - Eur. J. 2008, 14, $8562-8571$.

(16) Greindl, J.; Hioe, J.; Sorgenfrei, N.; Morana, F.; Gschwind, R. M. J. Am. Chem. Soc. 2016, 138, 15965-15971.

(17) Sorgenfrei, N.; Hioe, J.; Greindl, J.; Rothermel, K.; Morana, F.; Lokesh, N.; Gschwind, R. M. J. Am. Chem. Soc. 2016, 138, 1634516354.
(18) The E/Z-ratios experimentally found for a 1:1 mixture imine/ (R)-TRIP binary complexes at $300 \mathrm{~K}$ ranged from $80 / 20$ to $70 / 30$. The amount of $Z$ can be reduced preparing the sample at $180 \mathrm{~K}$.

(19) Metternich, J. B.; Gilmour, R. J. Am. Chem. Soc. 2016, 138, $1040-1045$.

(20) Metternich, J. B.; Gilmour, R. J. Am. Chem. Soc. 2015, 137, 11254-11257.

(21) Greb, L.; Eichhöfer, A.; Lehn, J.-M. Eur. J. Org. Chem. 2016, 2016, 1243-1246.

(22) Greb, L.; Eichhöfer, A.; Lehn, J.-M. Angew. Chem., Int. Ed. 2015, 54, 14345-14348.

(23) Greb, L.; Lehn, J.-M. J. Am. Chem. Soc. 2014, 136, 1311413117.

(24) Hsiao, C.-C.; Liao, H.-H.; Sugiono, E.; Atodiresei, I.; Rueping, M. Chem. - Eur. J. 2013, 19, 9775-9779.

(25) Iriepa, C. G.; Marazzi, M.; Frutos, L. M.; Sampedro, D. RSC Adv. 2013, 3, 6241-6266.

(26) Lehn, J.-M. Chem. - Eur. J. 2006, 12, 5910-5915.

(27) Maeda, K.; Fischer, E. Isr. J. Chem. 1977, 16, 294-298.

(28) Padwa, A.; Albrecht, F. J. Am. Chem. Soc. 1974, 96, 4849-4857.

(29) Considering all combinations of TS, the mechanistic scenarios possible are eight, but this number can be reduced to four fixed the configuration of the catalyst and knowing the major enantiomer formed for the product. All scenarios are summarized in the SI. In the case more than two transition states contribute, this method would also allow to identify $Z$ only, $E$ only, or mixed transition states following the fingerprint pattern described in Figure $2 \mathrm{~b}$.

(30) Hoffmann, S.; Seayad, A. M.; List, B. Angew. Chem., Int. Ed. 2005, 44, 7424-7427.

(31) Rueping, M.; Sugiono, E.; Azap, C.; Theissmann, T.; Bolte, M. Org. Lett. 2005, 7, 3781-3783.

(32) Rueping, M.; Azap, C.; Sugiono, E.; Theissmann, T. Synlett 2005, 15, 2367-2369.

(33) Feldmeier, C.; Bartling, H.; Riedle, E.; Gschwind, R. M. J. Magn. Reson. 2013, 232, 39-44.

(34) Ortega, M.; Rodríguez, M. A.; Campos, P. J. Tetrahedron 2005, 61, 11686-11691.

(35) Singh, S.; Sharma, V. K.; Gill, S.; Sahota, R. I. K. J. Chem. Soc, Perkin Trans. 1 1985, 437-440.

(36) Singh, S.; Trehan, A. K.; Sharma, V. K. Tetrahedron Lett. 1978, 50, 5029-5030.

(37) Padwa, A.; Bergmark, W.; Pashayan, D. J. Am. Chem. Soc. 1969, 91, 2653-2660

(38) Results obtained for the asymmetric transfer hydrogenation catalyst screening of compound $\mathbf{2 a}$ : $(R)$-Rueping catalyst $\mathbf{1 b}=$ control: 49\% yield, 74\% ee; $365 \mathrm{~nm}$ LED: 74\% yield, 74\% ee; (R)-MacMillan catalyst $1 \mathrm{c}=$ control: $19 \%$ yield, $91 \%$ ee; $365 \mathrm{~nm}$ LED: $35 \%$ yield; $91 \%$ ee. All reactions were carried out employing imine $2 \mathrm{a}(0.36 \mathrm{mmol}, 1$ equiv), Hantzsch ester 3 ( 1.4 equiv) and $0.1 \mathrm{~mol} \%$ of catalysts (expect for catalyst $1 \mathrm{c}$ for which $10 \mathrm{~mol} \%$ were used) in $4.4 \mathrm{~mL}$ toluene.

(39) The effect of solvation on enantioselectivity is usually assumed to be an effect of the dielectric constant of the solvent on the ion pairing equilibrium as reported by Brak, K.; Jacobsen, E. N. Angew. Chem., Int. Ed. 2013, 52, 534-561.

(40) All calculations were done at B2K-PLYP/CBS//TPSS-D3/def2SVP level of theory in the gas phase. Vibrational and thermochemical analysis were calculated at TPSS-D3/def2-SVP. Solvent correction was added using CPCM in toluene. For the geometry optimization frequency analysis and solvent correction the software package Gaussian 09 Revision D.01 was used. For the single points calculations ORCA 3.0.3 was used. More details for calculations were provided in the SI.

(41) Frisch, M. J.; Trucks, G. W.; Schlegel, H. B.; Scuseria, G. E.; Robb, M. A.; Cheeseman, J. R.; Scalmani, G.; Barone, V.; Mennucci, B.; Petersson, G. A.; Nakatsuji, H.; Caricato, M.; Li, X.; Hratchian, H. P.; Izmaylov, A. F.; Bloino, J.; Zheng, G.; Sonnenberg, J. L.; Hada, M.; Ehara, M.; Toyota, K.; Fukuda, R.; Hasega-wa, J.; Ishida, M.; Nakajima, T.; Honda, Y.; Kitao, O.; Nakai, H.; Vreven, T.; Montgomery, J. A., Jr.; Peralta, J. E.; Ogliaro, F.; Bearpark, M.; Heyd, J. J.; Brothers, E.; Ku- 
din, K. N.; Staroverov, V. N.; Kobayashi, R.; Normand, J.; Raghavachari, K.; Rendell, A.; Burant, J. C.; Iyengar, S. S.; Tomasi, J.; Cossi, M.; Rega, N.; Millam, J. M.; Klene, M.; Knox, J. E.; Cross, J. B.; Bakken, V.; Adamo, C.; Jaramillo, J.; Gomperts, R.; Stratmann, R. E.; Yazyev, O.; Austin, A. J.; Cammi, R.; Pomelli, C.; Ochterski, J. W.; Martin, R. L.; Morokuma, K.; Zakrzewski, V. G.; Voth, G. A.; Salvador, P.; Dannenberg, J. J.; Dapprich, S.; Daniels, A. D.; Farkas, Ö.; Foresman, J. B.; Ortiz, J. V.; Cioslowski, J.; Fox, D. J. Gaussian 09, Revision D.01; Gaussian, Inc.: Wallingford, CT, 2009.

(42) Neese, F. WIREs ComputMol. Sci. 2012, 2, 73-78.

(43) The combination of pathways Type I $E$ vs Type I $Z$ yields to almost $100 \%$ ee (barrier height difference of $15.4 \mathrm{~kJ} / \mathrm{mol}$ ). Other combinations result to the inverted enantiomeric products.

(44) Johnson, E. R.; Keinan, S.; Mori-Sánchez, P.; Contreras-García, J.; Cohen, A. J.; Yang, W. J. Am. Chem. Soc. 2010, 132, 6498-6506.

(45) Contreras-García, J.; Johnson, E. R.; Keinan, S.; Chaudret, R.; Piquemal, J. P.; Beratan, D. N.; Yang, W. J. Chem. Theory Comput. 2011, 7, 625-632. 